\title{
COMPLIMENTRY MEDICAL PRACTICES AMONG PATIENTS WITH DIABETES: T'HE SRI LANKAN PERSPECTIVE
}

\author{
Perera MPG'1, Hapuarachchi JC1, Nawagamuwa US'1. \\ ${ }^{1}$ Diabetes and Endocrine Unit, North Colombo Teaching Hospital, Ragama
}

\begin{abstract}
Alternative medicine is a group of diverse medical and health care systems, practices, and products that are not presently considered to be part of conventional medicine. If such a practice is used together with conventional medicine, it is considered "complementary" and if such a practice is used in place of conventional medicine, it is considered "alternative." Natural products such as herbal remedies, mind and body practices such as yoga, chiropractic and osteopathic manipulations, meditation, massage therapy, acupuncture,

use of herbal remedies and this practice is common among patients with type 2 diabetes. A cross-sectional study performed at Teaching Hospital Peradeniya has concluded that the use of a CAM to reduce blood glucose was as high as $76 \%$ and female gender was significantly associated with CAM use $(p=0.01)$ (7). Commonly used herbal remedies for blood glucose reduction are cinnamon (Cinnamomum cassia, Cinnamomum reylanicum), bitter gourd (Momordica charantia), crepe ginger (Costus speciosus), ivy gourd (Coccinia grandis) and fenugreek (Trigonella foemumgraecum).
\end{abstract} relaxation techniques such as breathing exercises, guided imagery and progressive muscle relaxation, tai chi, qi gong, healing touch, hypnotherapy, movement therapies, and other wellknown medical practices such as Ayurvedic medicine, traditional Chinese medicine, homeopathy and naturopathy are some of these alternative medical practices (1). These medical practices existed for centuries and different communities have been utilizing these alternative methods in different proportions. During the last few decades, there is an emerging trend towards the use of complementary and alternative medications (CAM) especially for chronic diseases. Diabetes being an uncurable chronic disease has a considerable attraction towards these types of medicines and studies have shown that the patients with diabetes are 1.6 times more likely than nondiabetics to use complementary medicines (2). However, there is little evidence to indicate that CAM approaches have been valuable in most the instances (3).

The worldwide prevalence of CAM use among patients with diabetes ranges between 30\%-57\% (4, 5, 6). Sri Lanka, a country with a rich culture of Ayurvedic medicine, has a very high
Cinnamon is used for the prevention and treatment of many ailments such as metabolic syndrome, insulin resistance, type 2 diabetes mellitus, hyperlipidaemia and arthritis (8). Several in-vitro studies have shown that cinnamon can increase glucose entry into cells by enhancing the insulin receptor phosphorylation and translocation of the glucose transporter GLUT4 to the plasma membrane (9). Animal studies have shown that cinnamon increases the activity of Pyruvate Kinase (PK) and decreases the activity of Phoshoenol Pyruvate Carboxy Kinase promoting glycogenesis and inhibiting gluconeogenesis (10). Cassia cinnamon also contains high levels of coumarins, profile of a patient who is simultaneously on drugs such as warfarin (11). Therefore, unsupervised use of these herbal remedies could lead to problems in such patients.

Studies have demonstrated that all the hypoglycaemic properties and that the plant extracts have structural similarities to animal insulin (12). These extracts have also shown to up regulate GLUT4, PI3K and PPAR gamma, thus which can affect the blood coagulation parts of bitter gourd plant exhibit increasing cellular glucose uptake (13). In an animal study, feeding of alcoholic extract from $M$. charantia has shown a definite improvement in the islets of Langerhans (14). However, there are reports of hypoglycemic coma and convulsions in children, reduced fertility in mice, a favism-like syndrome, increases in gammaglutamyltransferase and alkaline phosphatase levels in animals, and headaches with the use of bitter gourd (15).

Leaves of crepe ginger or 'thebu kola' is a famous, traditional Sri Lankan dish among patients with diabetes due to its hypoglycaemic properties. In addition to its antihyperglycaemic effects, the ethanol extract of the roots of this plant has demonstrated antihyperlipidaemic and antioxidant effects (16). Traditionally, it has been used as a salad for generations without any adverse effects. However, data on safety and toxicity on regular usage as a herbal remedy is limited.

Leaves of ivy gourd (also known as baby water melon) are also used to prepare a famous dish among diabetics. Manjula et al. have demonstrated a significant reduction in blood glucose and cholesterol levels when patients are treated with ivy gourd over a period of 21 days (17) and there has not been any adverse event reported in the literature with the administration of this herbal remedy.

Hypoglycaemic and antitriglyceridaemic properties of fenugreek seeds were evident in several studies and it has demonstrated the ability of improve insulin resistance (18). Even for this herbal remedy, there appears to be no 
significant adverse effects with the traditional way using it in the preparation of Asian delicacies.

Most of these herbal agents are in use for several decades and appear to be safe in small amounts. Since most of the studies are carried out on animal models, there is a risk of interactions and toxicity when they are tested on humans. Adequately powered, randomized, placebo-controlled trials are needed to properly assess the efficacy and the safety and to develop these products as clinically useful agents before recommending to patients. It is also important to raise awareness among the public regarding the pros and cons of using complementary and alternative medicine for diabetes mellitus. Most of these herbal agents are in use for several decades and appear to be safe in small amounts. Since most of the studies are carried out on animal models, there is a risk of interactions and toxicity when they are tested on humans. Adequately powered, randomized, placebo-controlled trials are needed to properly assess the efficacy and the safety and to develop these products as clinically useful agents before recommending to patients. It is also important to raise awareness among the public regarding the pros and cons of using complementary and alternative medicine for diabetes mellitus.

\section{REFEERENCES}

1. National Center for complimentary and integrative health, Complementary, Alternative, or Integrative Health: What's in a Name? Available at: https:// nccih.nih.gov/health/integrative-health (Accessed 16 March 2017).

2. Garrow D, Egede LE. Association between complementary and alternative medicine use, preventive care practices, and use of conventional medical services among adults with diabetes. Diabetes Care 2006; 29(1): 15-19.

3. Ernst E, Terry R. NICE Guidelines on Complementary/ Alternative Medicine: More Consistency and Rigour are Needed. The British journal of general practice 2009; 59(566): 695

4. Bell RA, Suerken C, Gryzwacz JG, Quandt SA, Arcury TA. Complementary and alternative medicine use among adults with diabetes in the United Sates. Alternative Therapies in Health and Medicine 2006; 12(5): 16-22.

5. Thomas KJ, Nicholl JP, Coleman P. Use and expenditure on complementary medicine in England: a population based survey. Complementary Therapies in Medicine 2001; 9(1): 2-11.

6. Manya K, Champion B, Dunning T. The use of complementary and alternative medicine among people living with diabetes in Sydney. BMC Complementary and Alternative Medicine 2012; 12: 2-10.

7. Medagama AB, Bandara R, Abeysekera RA, Imbulpitiya B, Pushpakumari T. Use of Complementary and Alternative Medicines (CAMs) among type 2 diabetes patients in Sri Lanka: a cross sectional survey. BMC complementary and alternative medicine 2014; 14: 374.

8. Rafehi H, Ververis $\mathrm{K}$, Karagiannis TC. Controversies surrounding the clinical potential of cinnamon for the management of diabetes. Diabetes obesity and metabolism 2012; 14(6): 493-499.

9. Choi K, Kim YB. Molecular mechanism of insulin resistance in obesity and type 2 diabetes. The Korean journal of internal medicine 2010; 25(2): 119-129.

10. Anand P, Murali KY, Tandon V, Murthy PS, Chandra R. Insulinotropic effect of cinnamaldehyde on transcriptional regulation of pyruvate kinase, phosphoenolpyruvate carboxykinase, and GLUT4 translocation in experimental diabetic rats. Chemico-Biological Interactions 2010; 186: 72-81.

11. Kawatra P, Rajagopalan R. Cinnamon: Mystic powers of a minute ingredient. Pharmacognosy research 2015; 7(Suppl 1): S1-S6.

12. Basch E, Gabardi S, Ulbricht C. Bitter melon (Momordica charantia): a review of efficacy and safety. American Journal of Health System Pharmacy 2003; 60(4): 356359

13. Zhu Y, Dong Y, Qian X, Cui F, Guo Q, Zhou $\mathrm{X}$, et al. Effect of superfine grinding on antidiabetic activity of bitter melon powder. International Journal of Molecular Sciences 2012; 13(11): 14203-14218.

14. Singh N, Gupta M, Sirohi P, Varsha. Effects of alcoholic extract of Momordica charantia (Linn.) whole fruit powder on the pancreatic islets of alloxan diabetic albino rats. Journal of Environmental Biology 2008; 29(1): 101-106.

15. Basch E, Gabardi S, Ulbricht C. Bitter melon (Momordica charantia): a review of efficacy and safety. American Journal of HealthSystem Pharmacy 2003; 60(4): 356-359.

16. Bavarva JH, Narasimhacharya AVRL. Antihyperglycemic and hypolipidemic effects of Costus speciosus in alloxan induced diabetic rats. Phytotherapy research 2008; 22(5): 620-626.

17. Manjula S, Ragavan B. Hypoglycemic and Hypolipidemic effect of Coccinia indica Wight \& Arn in alloxan induced diabetic rats. Ancient Science of Life 2007; 27(2): 34-37.

18. Gupta A, Gupta R, Lal B. Effect of Trigonella foenum-graecum (fenugreek) seeds on glycaemic control and insulin resistance in type 2 diabetes mellitus: a double-blind placebo controlled study. Journal of the Association of Physicians of India 2001; 49: 1057-1061. 